NASA Technical Memo, anduni 102Z30-

\title{
Wave Combustors for Trans-Atmospheric Vehicles
}

Gene P. Menees, Henry G. Adelman, Jean-Luc Cambier, and Jeffrey V. Bowles

October 1989

$(N A S A-T M-102 \angle 3 B)$ NAV CJMJUSTUOS FTR

$\sqrt{70}-1142$

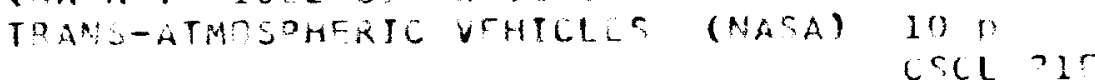

$$
=3 / 07 \quad 023 \% 07
$$


$-\sim$ 
NASA Technical Memorandum 102238

\section{Wave Combustors for Trans-Atmospheric Vehicles}

Gene P. Menees, Ames Research Center, Moffett Field, California Henry G. Adelman and Jean-Luc Cambier, Eloret Institute, Palo Alto, California Jeffrey V. Bowles, Ames Research Center, Moffett Field, California 



\title{
WAVE COMBUSTORS FOR TRANS-ATMOSPHERIC VEHICLES
}

\author{
Gene P. Menees* \\ NASA-Ames Research Center, Moffett Field, California \\ Henry G. Adelman ${ }^{\dagger}$ \\ Jean-Luc Cambier ${ }^{\ddagger}$ \\ Eloret Institute, Palo Alto, California \\ Jeffrey V.Bowles ${ }^{\S}$ \\ NASA-Ames Research Center, Moffett Field, California
}

\begin{abstract}
The Wave Combustor is an airbreathing hypersonic propulsion system which utilizes shock and detonation waves to enhance fuel-air mixing and combustion in supersonic flow. In this concept, an oblique shock wave in the combustor can act as a flameholder by increasing the pressure and temperature of the air-fuel mixture and thereby decreasing the ignition delay. If the oblique shock is sufficiently strong, then the combustion front and the shock wave can couple into a detonation wave. In this case, combustion occurs almost instantateously in a thin zone behind the wave front. The result is a shorter, lighter engine compared to the scramjet. This engine, which is called the Oblique Detonation Wave Engine (ODWE), can then be utilized to provide a smaller, lighter vehicle or to provide a higher payload capability for a given vehicle weight. An analysis of the performance of a conceptual trans-atmospheric vehicle (TAV) powered by an ODWE is given here.
\end{abstract}

\section{Nomenclature}

$\begin{array}{ll}C_{T} & =\text { thrust coefficient } \\ I_{s p} & =\text { specific impulse } \\ L / D & =\text { lift-to-drag ratio } \\ L E O & =\text { Low Earth Orbit } \\ l / h & =\text { combustor length-to-height ratio } \\ O D W E & =\text { Oblique Detonation Wave Engine } \\ M & =\text { mach Number } \\ q & =\text { dynamic pressure } \\ T A V & =\text { Trans-Atmospheric Vehicle } \\ T_{f} & =\text { fuel total temperature } \\ \phi & =\text { equivalence ratio }\end{array}$

\footnotetext{
*Research Scientist, Associate Fellow, AIAA

$\dagger$ Research Scientist, Member AIAA

$\ddagger$ Research Scientist, Member AIAA

${ }^{5}$ Research Scientist, Member, AIAA
}

\section{Introduction}

Investigations of wave enhanced supersonic mixing and combustion have been pursued for several decades. Detonation wave engines were reported in the 1940 ' $\mathrm{s}^{1}$, and studies of engines using moving and stationary detonation waves followed ${ }^{2-7}$. Enhancement of fuel mixing and combustion by shock waves has been investigated more recently ${ }^{8,9}$.

The experimental and analytical program at NASAAmes Research Center on wave enhanced mixing and combustion has been reported previously ${ }^{10-12}$. Experimental mixing and combustion studies are being carried out in a $20 \mathrm{MW}$ arc heated wind tunnel. Analytical studies include computer predictions of fuel injection, mixing and combustion using a 2-D, viscous fluid dynamic simulation with finite rate chemistry. In addition, candidate vehicle designs are studied using design codes for aerodynamics, structures, thermal protection systems, propulsion and trajectories.

\section{Propulsion Modeling}

A propulsion system model has been constructed to provide ODWE and scramjet engine performance data for the vehicle design and trajectory codes. This propulsion model provides inlet-to-nozzle details. The inlet compression process is modeled with multiple oblique shocks, including the bow shock. The inlet operates at the bow shock-on-cowl-lip design point for all Mach numbers. This is made possible by moving the cowl forward and aft during flight. A constant area combustor is also assumed.

For the scramjet case, the inlet operates in a four shock mode which gives good performance over all flight conditions. However, for the ODWE case, the oblique detonation wave acts as a diffuser, so fewer inlet shocks are 
needed. In this mode, two inlet shocks are sufficient. The shock system for both cases is shown in Figure 1.

The viscous and pressure drag forces from nose-to- tail on the underbody or engine side of the vehicle are accounted for in the two engine performance parameters, specific impulse and thrust coefficient. The thrust coefficient is defined as the thrust nomalized by the product of dynamic pressure and capture area. Engine specific impulse is obtained by dividing thrust by the fuel weight flow rate. The remaining vehicle drag not accounted for in the thrust coefficient, which includes the top, sides, cowl bottom surface and control surfaces is assigned to the vehicle aerodynamic characteristics.

For the low speed flight regime, below Mach 6, a hypothetical airbreathing engine with an average effective specific impulse of $1000 \mathrm{~s}$ and a thrust-to-weight ratio of 20 is used. Effective specific impulse is obtained by dividing the effective thrust (thrust minus vehicle drag) by the fuel weight flow rate. At high Mach numbers and altitudes, where the air-breathing engine thrust is diminished, a rocket engine with a thrust-to-weight ratio of 1.5 provides the final injection into orbit.

The efficiency of the propulsion system depends on various factors including the flight Mach number, dynamic pressure, forebody shape, fuel temperature and equivalence ratio. These factors are discussed in the results section.

\section{Vehicle Modeling}

Performance and sizing estimations were made using a hypersonic vehicle synthesis code for trans-atmospheric designs. This code was orginally developed at NASAAmes to model hypersonic cruise aircraft ${ }^{13}$ and it has since been modified to study trans-atmospheric designs. Estimates can be made of aerodynamic characteristics, aero-thermal heating, propulsion system performance and structural/subsystem weights. An automated vehicle closure algorithm iterates the trajectory analysis to close the design on both vehicle weight and volume.

The aero-thermal analysis consists of a series of performance estimates based on Mach number regime. For subsonic, transonic, and low supersonic speeds (below the critical Mach number), a set of empirical relations are used which are based on overall vehicle geometric characteristics. In the mid to high supersonic regime, real gas tangent cone/wedge models are used. Newtonian flow is assumed to determine the hypersonic pressure coefficient. Skin friction and heat transfer models are based on a reference enthalpy method ${ }^{14}$.

Structural analysis is based on simplified beam theory, using the aero-induced loads to compute the longitudinal bending moment distribution. Longitudinal and internal pressure loads are also accounted for in the structural stresses. Additional checks on buckling, local instability and minimum gauge constraints, coupled with non-optimum fracture are then used to compute the required structural weight. The thermal protection system is sized according to the maximum temperatures and integrated heat loads over the mission. The high heating loads on the nose and wing leading edge will require active cooling systems ${ }^{15}$.

The trajectory analysis is then used to compute the required fuel fraction for the vehicle. The equations of motion are integrated over the specified Mach numberaltitude flight path to determine total fuel requirements and mission duration. Vehicle gross weight and volume are then iterated to find the closure point, that is where the required fuel fraction and the available fuel fraction are equal.

To size the vehicles, a mission was selected which carried a payload of 15,000 pounds into a Low Earth Orbit (LEO) of 120 nautical miles altitude. A horizontal takeoff in the easterly direction from Kennedy Space Center was assumed, with an on-station duration of six hours. Two ascent trajectories were studied, with dynamic pressures of 1000 and 2000 pounds per square foot (psf). The flight path was constrained to give 100 psi duct pressure at lower supersonic Mach numbers and a maximum mean surface equilibrium radiation temperature of $2000 \mathrm{~F}(1367 \mathrm{~K})$ for high Mach numbers. The speed at which the airbreathing engine thrust was augmented by a rocket was optimized to minimize the gross takeoff weight. A descent trajectory was flown near peak L/D to maximize the descent cross-range capability. Fuel reserves of $2 \%$ of mission fuel were assumed for the landing maneuver.

\section{Results}

\section{General Vehicle Design}

The general vehicle configuration, shown in Figure 2, is a lifting body with aft mounted horizontal and vertical tails. Planform shape is a power-law configuration with a fore-body lower surface angle of 5.5 degrees and a nozzle chord angle of 9.5 degrees. The cross-sectional shape consists of upper and lower near elliptical sections with 
major- to-minor axis ratios of 4 for the upper surface and 2 for the lower surface. The vehicle break-point (transition from fore body to aft body) is at $65 \%$ of the body length and the fatness ratio (maximum cross sectional area to planform area) is $9.7 \%$. Engine width is $67 \%$ of the maximum width which provides adequate room for the main landing gear. The total propulsion system consists of two airbreathing engines, one for Mach numbers below 6 , and a scramjet or an ODWE for the remaining part of the flight. In addition, a rocket engine is used in conjuction with the air-breathing engine for the high altitude, high Mach number portion of the trajectory. Liquid hydrogen is the fuel for all engines.

Aero-thermodynamic characteristics of the vehicle were computed using the synthesis code methods. The structural design incorporated a cool integral tank concept where the tank carries both the aero-induced bending loads as well as the internal tank pressure loads. Sufficient thermal insulation is used to maintain the tank material temperature limits and minimize the hydrogen boil-off. With a design condition of $2.0 \mathrm{~g}$ 's at Mach 6 , the unit structural weight was somewhat less than 4.0 $\mathrm{lb} / \mathrm{ft}^{2}$.

\section{General Engine Performance}

The results of the engine performance calculations show that specific impulse and thrust coefficients depend on dynamic pressure, combustion efficiency, fuel temperature and equivalence ratio. Certain trends can be observed. As shown in Figure 3, it is evident that higher heat recycling from the engine leads to higher injected fuel temperatures and larger values of specific impulse and thrust coefficient. We assume that the fuel is injected at a constant Mach number of 2.5. As more heat is added to increase the stagnation temperature, significant momentum can be gained from the fuel injection. However, fuel temperature is limited by the amount of heat which can be absorbed from the structure and by the temperature limits of the materials used to store and transport the fuel. In this study, we will assume that $90 \%$ of the heat loads have been absorbed by the fuel. The fuel is then heated to a limiting temperature of $1100 \mathrm{~K}(1520 \mathrm{~F})$, which is representative of the current materials available for fuel storage and transport. If this temperature limit is exceeded, then an amount of fuel in excess of stoichiometric must be used. The resulting equivalence ratio versus Mach number schedule for the scramjet is shown in Figure 4 for various fuel temperature limits.

Since the ODWE combustor is shorter, a stoichiometric mixture can be maintained to a Mach number of 17.5 compared to 14 for the scramjet, for a fuel temperature of $1100 \mathrm{~K}$. While heat recycle increases engine performance for stoichiometric mixtures, the effect of using excess fuel to maintain a specified temperature limit may increase the thrust coefficients but will lower the specific impulses as shown in Figure 5. It is clear that the cooling requirements seriously affect the performance of the engine at high Mach numbers.

Flight trajectories were assumed for constant dynamic pressures of 1000 and 2000 psf which bracket the range expected for airbreathing vehicles. Higher dynamic pressures, above 2000 psf, provide slightly greater specific impulses and thrust coefficients, but may impose higher heating loads on the vehicle which could increase thermal protection system weights, or exceed the 2000 F temperature limit.

Engine performance is also influenced by combustion and mixing efficiencies. Combustion efficiency is limited by the amount of fuel which can be converted to water at the conditions in the combustor. This is determined by the hydrogen-oxygen- water equilibrium constant. Combustion efficiencies at stoichiometric air-fuel ratios range from $93.5 \%$ at Mach 8 to $86.8 \%$ at Mach 20 . Higher equivalence ratios provide excess fuel which lowers combustion temperatures and raises combustion efficiencies. However, while specific impulse values decrease, thrust coefficients increase due to the fact that there is momentum recovered from the hot excess fuel. Combustion efficiency can be increased if there is recombination of the dissociated products in the nozzle. Since the amount of recombination was not a subject of this study, we have assumed that it is substantial and we have assigned an overall combustion efficiency of $100 \%$ to the propulsion system.

The extent of mixing and combustion will depend on the injector design and the combustor length. We have selected a combustor length to height ratio $(1 / h)$ of 10 in this study for the scramjet and an $l / h$ of 1.5 for the ODWE. Due to the lack of extensive mixing and combustion data, mixing and combustion efficiencies were assumed to be $100 \%$ for both engines at all equivalence ratios.

\section{Scramjet Engine Performance}

The calculated performance of the scramjet engine is shown in Figure 6 as a function of Mach number for a dynamic pressure of $2000 \mathrm{psf}$ and an equivalence ratio schedule which maintains the fuel temperature below 
$1100 \mathrm{~K}$. It can be seen that the specific impulse begins to drop at Mach 14 due to the rise in equivalence ratios necessary to maintain the $1100 \mathrm{~K}$ fuel temperature limit.

\section{ODWE Performance}

The ODWE performance was also calculated for dynamic pressures of $1000 \mathrm{psf}$ and $2000 \mathrm{psf}$. In Figure 6 we compare the performance of both the scramjet and ODWE for the $q=2000 \mathrm{psf}$ case. It appears that the ODWE has a better performance than the scramjet at high Mach numbers, but has lower specific impulse below Mach 15. The reduced performance at low Mach numbers is due to the steep wave angle of an oblique Chapman-Jouguet (CJ) detonation, and therefore to higher shock losses. The wave angle can be reduced if either the Mach number is increased or the ChapmanJouguet Mach number is decreased (i.e. the static temperature prior to the detonation wave is increased or $\phi$ is decreased). Therefore, the ODWE favors operation at high Mach numbers.

The ODWE also takes advantage of a shorter combustor which requires less cooling and less excess fuel at higher Mach numbers than the scramjet. It can be seen in Figure 6 that the knee in the specific impulse curve, which indicates the start of the excess fueling schedule, begins at a higher Mach number for the ODWE than for the scramjet. Since the problems of mixing and ignition delay impose a long combustor for high Mach numbers, it is clear that increasing the combustor length forces the performance of the scramjet to drop at lower Mach numbers, when the fuel must be injected in excess of stoichiometric.

For the ODWE, the benefits of a shorter combustion chamber, which results in a shorter, lighter engine will also be evident in the vehicle size and weight calculations which are discussed later.

\section{Scramjet Vehicle Performance}

A scramjet powered vehicle was modeled using the predicted engine performance data. The vehicle weight breakdowns are shown in Table 1 for the trajectory of constant dynamic pressure $q=2000 \mathrm{psf}$. Since the scramjet is very inefficient below Mach 6, a hypothetical engine system with an average effective specific impulse of $1000 \mathrm{~s}$ was used to propel the vehicle from horizontal takeoff to Mach 6 . Since the effective specific impulse takes into account the aero-dynamic drag on all surfaces (not just the inlet, combustor and nozzle), it is significantly less than the engine specific impulse. Aerodynamic heating considerations required that the dynamic pressure of the flightpath, as shown in figure 7 , begins to drop below the specified value of 2000 psf at Mach 17 to about $250 \mathrm{psf}$ at Mach 22. This low dynamic pressure requirement at high Mach numbers necessitates rocket power augmentation which begins at Mach 18. The amount of thrust provided by the rocket is larger than the thrust produced by the scramjet, and the rocket thrust fraction continues to increase until orbital speeds are reached.

The vehicle which flies a 2000 psf trajectory weighs 460,512 pounds and carries a 15,000 payload into orbit. The scramjet engine, low speed engine and rocket motors comprise $8.6 \%$ of the takeoff weight. For comparative purposes, a vehicle which flies a 1000 psf trajectory was also studied. This TAV is heavier at 623,000 pounds. The main reason for the increased weight is the lower mass capture per unit area of inlet, which requires a larger, heavier engine and associated structure. Also, the lower thrust-to-weight ratio results in a longer flight time to orbit which consumes a greater amount of fuel.

\section{ODWE Vehicle Performance}

The hypersonic vehicle using the ODWE has somewhat different weight characteristics as shown in Table 2. Since the ODWE offers superior performance above Mach 15, the point of rocket turn-on is delayed to Mach 19. The ODWE can operate at higher Mach numbers than the scramjet, and continues to provide a higher fraction of airbreathing thrust to orbital speeds. Therefore, less rocket thrust is needed and a lower mass fraction of LOX is consumed, $12.5 \%$ versus $15.9 \%$ for the scramjet. This represents a weight savings of 22,000 compared to the scramjet. In addition, the shorter combustor length provided by the ODWE allows a shorter, lighter engine which saves about 5,000 pounds. The ODWE represents $3.7 \%$ of the gross weight, compared to $4.4 \%$ for the baseline scramjet engine. While the fuel weight fraction is higher for the ODWE, the actual fuel weight is 14,000 pounds lower. As a result of all these factors, the ODWE configuration weighs 409,500 pounds, some 51,000 pounds less than the scramjet vehicle (for $q=2000 \mathrm{psf}$ ), and carries the same payload of 15,000 pounds to orbit. Note that the payload weight fraction is increased from $3.3 \%$ of the takeoff weight for the scramjet to $3.7 \%$ for the ODWE.

\section{Conclusions}

The ODWE powered hypersonic vehicle shows different 
performance characteristics than the scramjet powered vehicle:

1. The ODWE trades a better engine performance above Mach 15 for a lower performance below Mach 15. This trade-off still favors the ODWE overall.

2. The better performance of the ODWE at higher Mach numbers allows a delay of the rocket augmentation mode, and results in a lower mass of LOX required for orbit insertion.

3. The smaller ODWE allows another direct weight reduction of $\simeq 5,000 \mathrm{lbs}$.

4. The overall higher performance of the ODWE results in a weight savings of 51,000 pounds and a higher payload weight fraction of approximately $12 \%$.

Since the scramjet has better performance below Mach 15 , and the ODWE above Mach 15, a combination of these two engines may be ideal. This hybrid engine would use a two-shock diffuser for the whole Mach range. At low Mach numbers, the mixing length and ignition requirements are less severe, and a relatively short combustor can be used in a scramjet mode. At higher Mach numbers, the diffusing shocks would move aft into the combustor. The engine would operate in the oblique detonation mode in the aft section of the combustor. Therefore, cooling is required only for a fraction of the combustor, and the drop in performance due to cooling requirements would still occur only at very high Mach numbers. The design of such a hybrid engine would require more sophisticated, two-dimensional analysis. Work in that direction is progressing.

\section{Aknowledgement}

The authors wish to thank Dr. D.W. Bogdanoff for providing an initial version of a one-dimensional analysis code for scramjet engine performance, which was subsequently modified for our study.

\section{References}

1. Roy M., Comptes Rendus a l'Academy des Sciences, Feb., 1946.

2. Sargent W,M. and Gross, R.A., "A Detonation Wave Hypersonic Ramjet", AFOSR TN 59-589, 1959.
3. Townend L.H., "Detonation Ramjets for Hypersonic Aircraft", RAE Technical Report 70218, November 1970 .

4. Morrison R.B., "Evaluation of the Oblique Detonation Wave Hypersonic Ramjet", NASA Contractor Report 145358, January 1978.

5. Morrison R.B., "Oblique Detonation Ramjet", NASA Contractor Report 159192, January 1980.

6. Cambier J.L. and Adelman, H.G., "Preliminary Numerical Simulations of a Pulsed Detonation Wave Engine", AIAA paper 88-2960, July 1988.

7. Nichols J.A. et. al., "Intermittant Detonation as a Thrust-Producing Mechanism", Jet Propulsion, May, 1957, pp. 534-541.

8. Kumar A. et. al., "A Mixing Augmentation Technique for Hypervelocity Scramjets", AIAA paper 871882 .

9. Marble F.E., Hendricks, G.J. and Zukowski, E.E.," Progress Toward Shock Enhancement of Supersonic Processes", AIAA paper 87-1880, June, 1987.

10. Cambier J.L., Adelman, H.G. and Menees, G.P., "Numerical Simulations of Oblique Detonations in Supersonic Combustion Chambers", AIAA Journal of Propulsion and Power, vol. 5, No. 4, July-August 1989, pp. 482-491.

11. Adelman H.G. , Cambier, J.L. , Menees, G.P. and Balboni, J.A., "Analytical and Experimental Validation of the Oblique detonation Wave Engine Concept", AIAA paper 88-0097, January 1988.

12. Cambier J.L., Adelman, H.G. and Menees, G.P., " Numerical Simulations of an Oblique Detonation Wave Engine", AIAA paper 88-0063, January 1988.

13. Gregory T.J. et. al., "Hypersonic Transport Preliminary Performance Estimates for an All-Body Configuration", AIAA paper 70-1224, October 1970.

14. Eckert, E.R.G., "Survey on Heat Transfer at High Speeds", Aeronautical Research Laboratories, University of Minnesota, ARL 189, December, 1961.

15. Tauber M.E. and Adelman, H.G., "Thermal Environments of Transatmospheric Vehicles", AIAA Journal of Aircraft, vol. 25, No. 4, pp. 355-363, April 1988. 


\begin{tabular}{|l|r|}
\hline Component & Weight fraction \\
\hline Empty Weight & $28.0 \%$ \\
Structure & $18.4 \%$ \\
Propulsion Systems & $8.6 \%$ \\
Fixed Equipment & $1.1 \%$ \\
LH & $51.8 \%$ \\
LOX & $15.9 \%$ \\
Payload & $3.3 \%$ \\
\hline
\end{tabular}

Table 1: Scramjet vehicle data for fixed payload of 15,000 lbs. Fractions are relative to total take-off weight of $460,512 \mathrm{lbs}$ for $\mathrm{q}=2000 \mathrm{psf}$ trajectory.

\begin{tabular}{|l|r|}
\hline Component & Weight fraction \\
\hline Empty Weight & $27.9 \%$ \\
Structure & $18.8 \%$ \\
Propulsion Systems & $8.0 \%$ \\
Fixed Equipment & $1.1 \%$ \\
LH $_{2}$ & $54.8 \%$ \\
LOX & $12.5 \%$ \\
Payload & $3.7 \%$ \\
\hline
\end{tabular}

Table 2: ODWE vehicle data for fixed payload of 15,000 lbs. Fractions are relative to total take-off weight of 409,500 lbs for $q=2000$ psf trajectory.

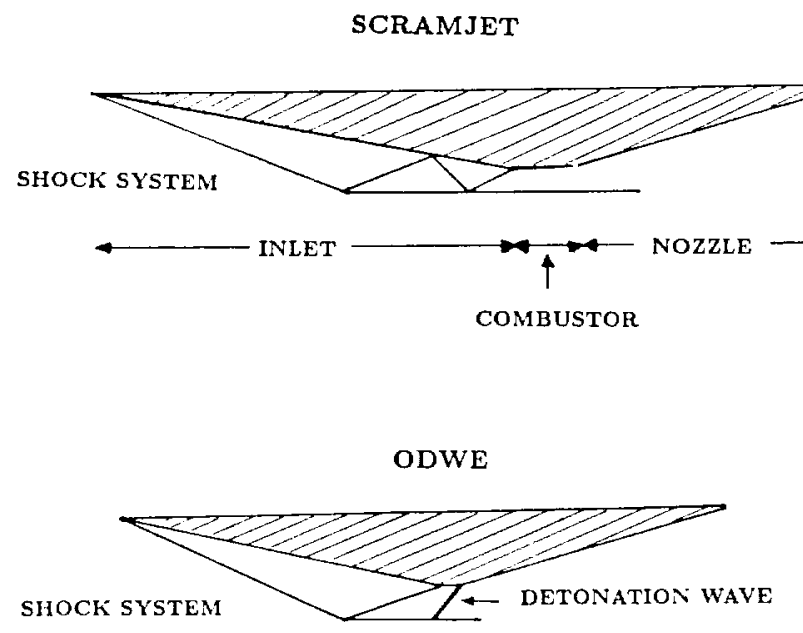

Figure 1: Schematic of shock structure for scramjet engine and ODWE, including detonation wave.
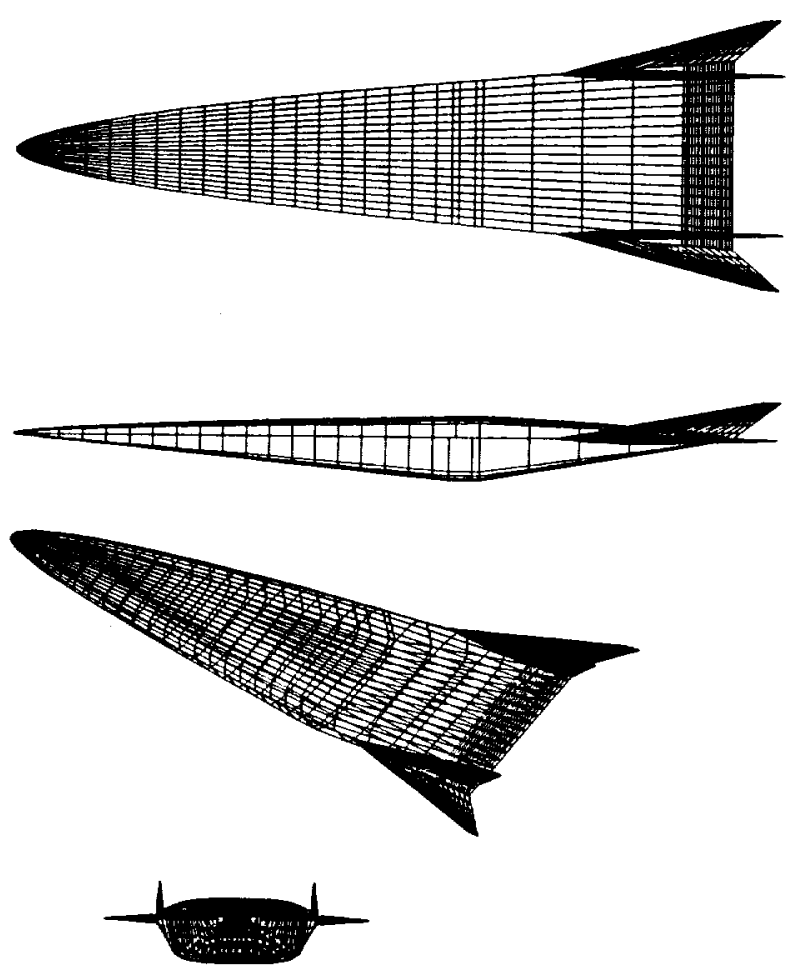

Figure 2: Schematics of generic TAV concept used in this study.

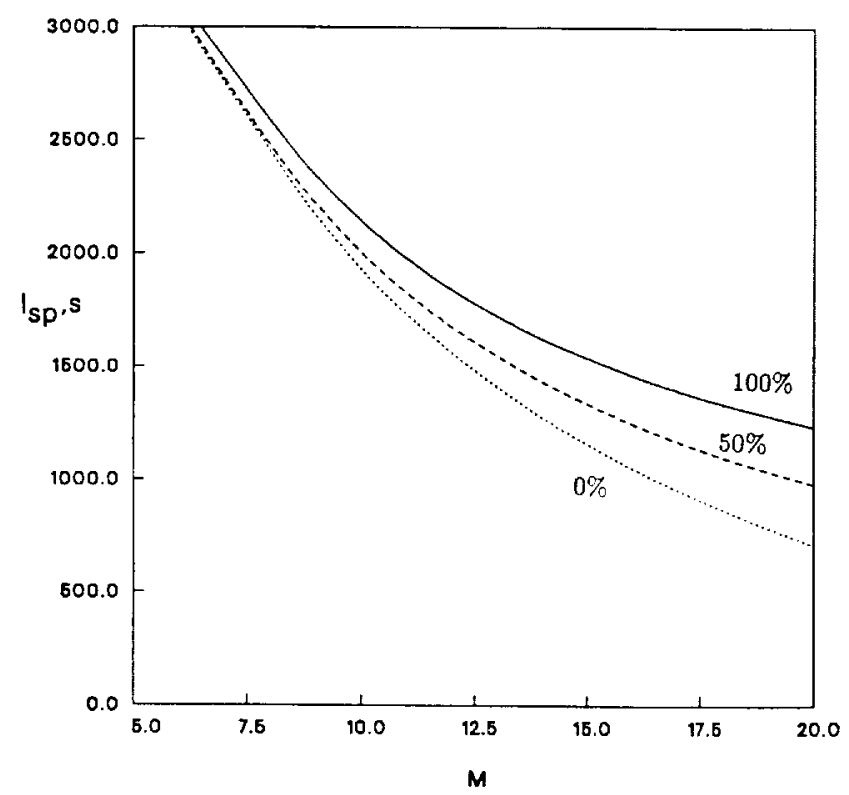

Figure 3: Specific impulse versus Mach number for scramjet engine ( $q=2000 \mathrm{psf}, \phi=1)$. Cases shown are for $0 \%, 50 \%$ and $100 \%$ of the heat loads absorbed into the fuel. 


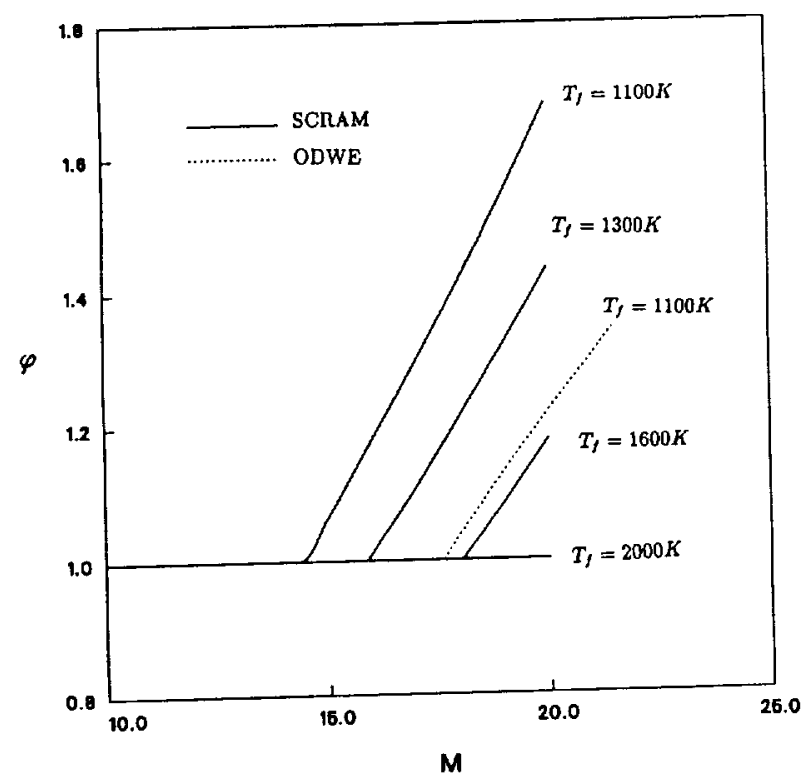

Figure 4: Equivalence ratio versus Mach number for scramjet and ODWE engines at $q=2000$ psf. ODWE results are shown for a fuel temperature limit of 1100 $K$, while scramjet results are shown for a temperature range from 1100 to $2000 \mathrm{~K}$ (1520 to $3140 \mathrm{~F})$.

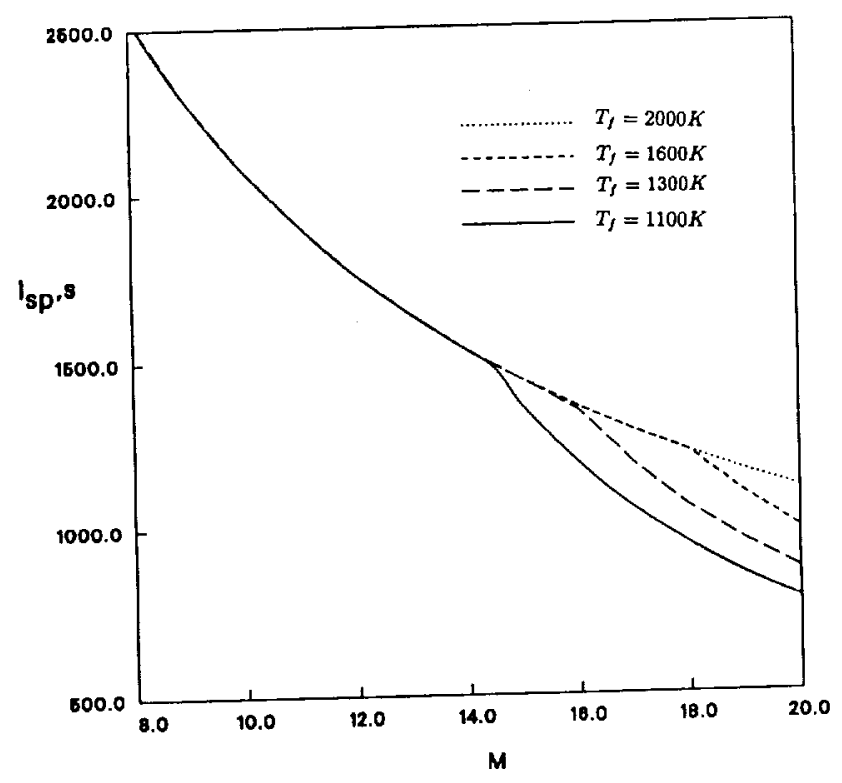

Figure 5: Specific impulse versus Mach number for scramjet engine at $q=2000$ psf. Results are for fuel temperature limits from 1100 to $2000 \mathrm{~K}$ (1520 to $3140 \mathrm{~F}$ ).

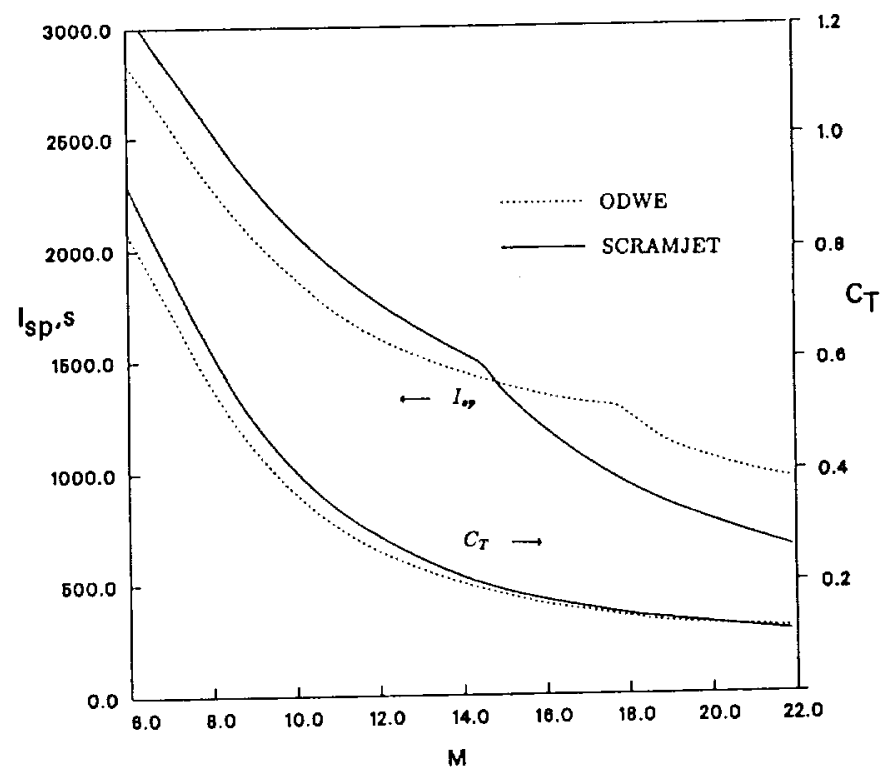

Figure 6: Comparison of scramjet and ODWE performance characteristics. Shown are $I_{s p}$ and $C_{T}$ profiles for $q=2000 \mathrm{psf}, 90 \%$ of heat loads carried by fuel and 1100 $\mathrm{K}$ fuel temperature limit.

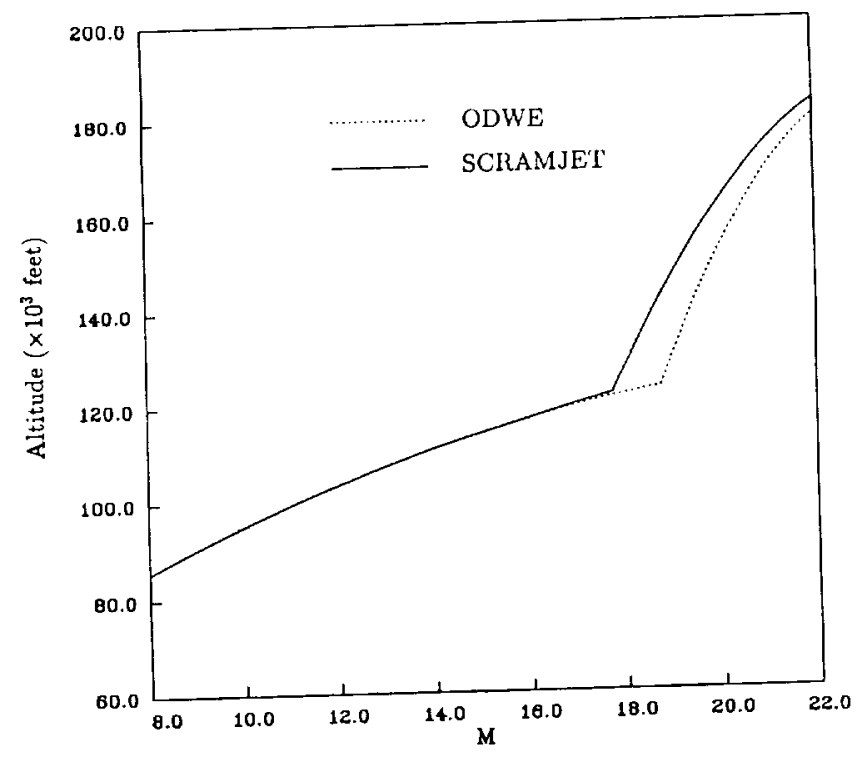

Figure 7: Comparison of flight trajectories at $q=\mathbf{2 0 0 0}$ psf for ODWE and scramjet vehicles. 


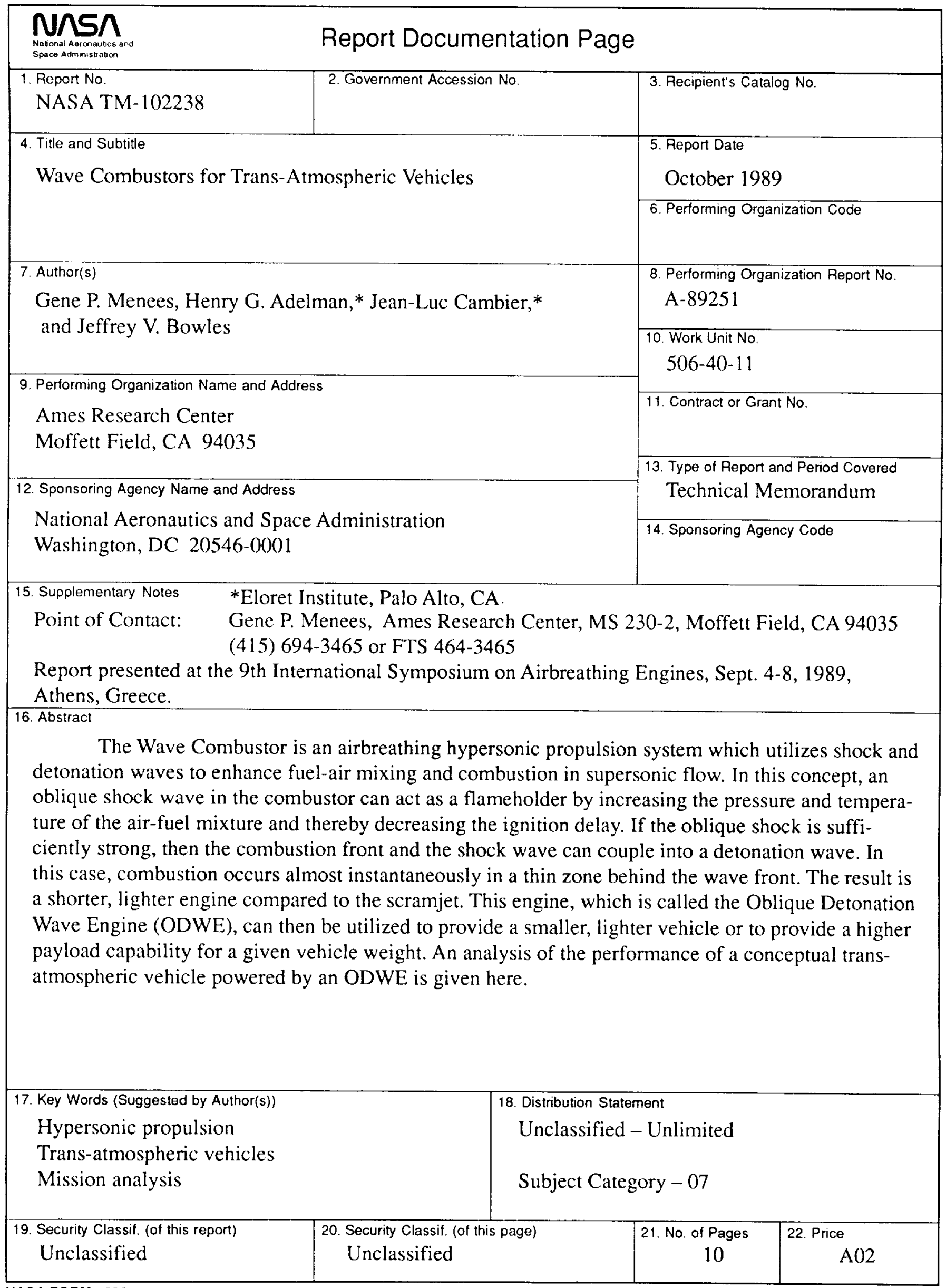



